\title{
AS TENDÊNCIAS IDEOLÓGICAS DOS CURSOS DE LICENCIATURA EM EDUCAÇÃO FÍSICA NA MODALIDADE A DISTÂNCIA
}

\begin{abstract}
THE IDEOLOGICAL TRENDS OF THE LICENSING COURSES IN PHYSICAL EDUCATION IN THE DISTANCE MODE

TENDENCIAS IDEOLÓGICAS DE LOS CURSOS DE GRADO EN EDUCACIÓN FÍSICA EN MODO DE DISTANCIA

Fernanda Cruvinel Pimentel'; Raquel de Almeida Moraes $^{2}$

\section{RESUMO}

O objetivo desta pesquisa consistiu em identificar e analisar as tendências ideológicas dos cursos de licenciatura em Educação Física a distância no estado de Goiás, tendo o materialismo histórico-dialético como princípio metodológico orientador. Para a coleta de dados, foram utilizadas as técnicas da pesquisa bibliográfica, documental e entrevista semiestruturada. Como conclusão, percebe-se que a formação na IES privada é primordialmente voltada para a empregabilidade, e na IES pública, por precarizar a atuação docente, dentre outras questões estruturais, a política da UAB dificulta uma ação formativa emancipadora, posto que está preza à lógica do capital. Logo, o problema não é a modalidade à distância em si, mas o fato de que no modo de produção capitalista, a EAD se torna um negócio muito lucrativo, comprometendo a qualidade da educação.
\end{abstract}

PALAVRAS-CHAVE Ideologia. Educação a distância. Educação Física.

\section{ABSTRACT}

In this research, we investigated the ideological tendencies of undergraduate courses of distance education in Physical Education in the state of Goiás, with historical-dialectical materialism as a guiding methodological principle. For data collection, the techniques of bibliographic, documentary and semi-structured interview were used. As a conclusion, it was realized that training in private $\mathrm{HEI}$ is primarily focused on employability, and the public $\mathrm{HEl}$, by precarious teaching performance, among other structural issues, perceived that the UAB policy, hinders a formative action more emancipatory. Therefore, the problem is not the distance modality itself, but the fact that under the domain of capital, ODL becomes a very lucrative business, compromising the quality of education.

KEYWORDS: Ideology. Distance education. Physical Education.

\footnotetext{
${ }^{1}$ Professora adjunto A no Centro de Estudo e Pesquisa Aplicada à Educação da Universidade Federal de Goiás (CEPAE/UFG). Doutora em Educação pela Universidade de Brasília (UnB). Mestre em Educação Física pela Universidade de Brasília (UnB). E-mail: fernandafefufg@gmail.com

${ }^{2}$ Professora Associada 4 da Universidade de Brasília. Doutora em Educação pela Universidade Estadual de Campinas (1996) e estudos pós-doutorais em Filosofia da Educação pela Universidade de Haifa (2004). E-mail: raquelmoraesbr@gmail.com
}

Submetido em: 21/08/2019 - Aceito em: 16/04/2020

(C) ETD-Educação Temática Digital $\quad$ Campinas, SP $\quad$ v.23 $\quad$ n.1 $\quad$ p. 82-97 jan./mar. 2021




\section{RESUMEN}

En esta investigación se investigaron las tendencias ideológicas de los cursos de grado de Educación Física a distancia en el estado de Goiás, teniendo el materialismo histórico-dialéctico como principio metodológico rector. Para la recolección de datos, utilizamos las técnicas de investigación bibliográfica, documental y entrevista semiestructurada. En conclusión, está claro que la capacitación en IES privadas se centra principalmente en la empleabilidad y la IES pública, ya que el desempeño precario de la enseñanza, entre otros problemas estructurales, a través de la política de la UAB, dificulta una acción formativa más emancipadora. Por lo tanto, el problema no es el modo a distancia en sí mismo, sino el hecho de que, bajo el dominio del capital, el aprendizaje a distancia se convierte en un negocio muy lucrativo, comprometiendo la calidad de la educación.

PALAVRAS-CLAVE: Ideologia. Educación a distancia. Educación física.

\section{INTRODUÇÃO}

Segundo a literatura na área, a formação em Educação Física (EF) ocorre historicamente em concordância com a tendência ideológica política e com a economia do período na qual está inserida. São fatores influenciadores já identificados historicamente: o higienismo/eugenia, o militarismo, a industrialização com os princípios de linha de produção, qualidade e produtividade, a indústria esportiva (PALAFON, 1993; SOARES et al., 1992), e mais recentemente a indústria "fitness".

Mas em vista disso, perguntamos: O que se entende por Ideologia?

Marx e Engels (2008), em "Contribuição à Crítica da Economia Política", entendem que mais que uma falsa visão da realidade, a ideologia expressa o interesse da classe dominante. Ao impor um conjunto de ideias e valores dessa classe como se fossem universais, estes devem ser seguidos e aceitos por todas as classes.

Meszáros (2008) afirma que “(...) a ideologia não é nem ilusão, nem superstição religiosa de indivíduos mal orientados, mas uma forma específica de consciência social, materialmente ancorada e sustentada (p. 65)". E como tal, não pode ser superada nas sociedades de classe.

$\mathrm{Na}$ economia política contemporânea, essas ideias são expressas pela ideologia neoliberal, que preceitua o seguinte: mínima participação estatal nos rumos da economia do país; pouca intervenção do governo no mercado de trabalho; total liberdade de comércio (livre mercado), tendo a base da economia formada por empresas privadas; privatização das empresas estatais; livre circulação de capitais internacionais; abertura da economia para a entrada de multinacionais. Dentre outros princípios básicos, o Brasil, na década de 1990, inicia um processo de reforma política com alterações no campo das políticas públicas e sociais.

A educação também é influenciada pela ideologia neoliberal que busca a qualidade, competição e individualismo expressos nas orientações dos Organismos internacionais (OI), Banco Mundial (BM) e Organização das Nações Unidas para a Educação, a Ciência e a Cultura (UNESCO), principalmente, com opções e interesses sociopolíticos bem determinados. Para Dourado (2008), há um crescimento desordenado de cursos e instituições privadas de ensino, principalmente faculdades, instituições de pequeno porte, centros universitários (instituições tipicamente de ensino), para assim atender as distintas necessidades provocadas pelo campo 
profissional, mercado de trabalho e classe social. Segundo Saviani (2010), esses cursos têm padrões menos exigentes de qualidade, devido à flexibilização acerca da expansão do ensino superior.

Em relação às reformas (ajuste neoliberal), o documento "Pryoridades y Strategias para la Educación", de 1996 (BANCO MUNDIAL, 1996), afirma que os países que não iniciaram as reformas necessárias na educação estavam dificultando as mudanças e não estavam contribuindo para reduzir seus índices de pobreza, atrasando o desenvolvimento econômico do país, considerando a evolução dos países desenvolvidos, sobretudo daqueles que estão investindo em capital humano.

Nesse mesmo documento de 1996, é afirmado que a formação dos profissionais da educação por meio da formação continuada em serviço tem maiores possibilidades se forem utilizadas as potencialidades da educação a distância (EAD - "los programas de educación a distância para formación pedagógica em El servicio suelen ser más eficaces em función de los costos que los programas de enzeñasas em internatos") (BANCO MUNDIAL, 1996, p. 112).

Importante essa passagem para se entender por qual motivoa palavra democratização precisa ser colocada entre aspas. Pois afinal, a educação pode estar até alcançando mais pessoas, mas com qual qualidade? Sob quais interesses?

Para Malanchen (2008), os OI, BM e Unesco, prescrevem que o ideal de progresso consiste em levar educação para todos como se fosse a chave mágica para o desenvolvimento humano e para o alívio da pobreza. Mas é importante aumentar os índices educacionais do país. A modalidade a distância então vai se destacar nesse cenário devido à possibilidade de flexibilização de tempo e espaço, alcançando maior número as pessoas e atendendo à "democratização" do acesso ao ensino superior.

A partir desses pressupostos, este artigo considera que a expansão e consolidação da formação de professores de EF a distância devem ser criteriosamente avaliadas para que o seu desenvolvimento não se dê apenas quantitativamente, mas, sobretudo, qualitativamente. Objetiva-se, aqui, expor o resultado da investigação acerca das tendências ideológicas desta formação, entendendo que a ideologia nunca explicita sua própria origem e possui uma coerência racional de ciência, moral, tecnologia, filosofia, religião, com lacunas que nunca poderão ser preenchidas para não se quebrar por dentro. Conforme Chauí (2008), a ideologia é uma ação que não diz tudo, não pode dizer tudo. 


\section{ASPECTOS HISTÓRICOS DA FORMAÇÃO SUPERIOR EM EDUCAÇÃO FÍSICA}

A fim de obter resposta à inquietação que se originou deste estudo, propomos a contextualização dos aspectos históricos da formação superior em EF, com ênfase nas diretrizes curriculares, na esportivização das aulas de EF e na divisão do curso em licenciatura e bacharelado com suas tensões e conflitos acerca da profissionalização da EF.

No contexto da formação profissional, Betti (1991) assinala que a formação de professores de EF no Brasil esteve muito ligada à história dos militares especialmente entre o período de 1930 a 1945. Segundo Cantarino Filho (1982, p.147),

Nessa época (estrutura curricular militarista) os professores de EF que ministravam as atividades físicas nos estabelecimentos de ensino primário e secundário, ou era autodidatas ou procediam, inicialmente do Centro Militar em EF, e mais tarde, da Escola de EF do Exército.

Em 1939, com a criação da Universidade do Brasil e da Escola Nacional de EF e Desportos (ENEFD) é criado o primeiro currículo de formação de profissionais de EF no Brasil. Era uma formação profissional de um ano para o instrutor de ginástica, o técnico em massagem, o técnico desportivo, e de dois anos para o professor de EF. A duração deste curso passa para três anos, após ter sido estabelecida a obrigatoriedade da EF no sistema educacional brasileiro, e ganhado uma atenção especial na Lei de Diretrizes e Bases de 1961 (SOUZA NETO, et.al., 2004). O modelo de currículo também se modifica, incluindo, , mais disciplinas pedagógicas para o profissional direcionado para a escola, entretanto, o aspecto esportivo técnico era o conteúdo predominante nas aulas de EF (AMARAL, et.al., 2006).

Nesse contexto, a partir da década de 80, surge os primeiros elementos de uma crítica à sua função sócio-política conservadora dentro da escola (COLETIVO DE AUTORES, 1992; BRACHT, 1999, 2000; VAGO,1996), notabilizando que a EF deveria se soltar das amarras do ensino técnico, utilitarista, instrumental e reprodutor que estiveram presentes no conteúdo da EF durante toda a sua história, para se comprometer aos propósitos de formação para emancipação crítica dos sujeitos. No entanto, apesar dos avanços na prática pedagógica, ainda hoje o cordão umbilical do esporte (instituição esportiva) não foi banido da EF escolar (CAPARROZ, 2007; AZEVEDO, BERGMAN, 2013).

No cenário atual, com o surgimento de novas ocupações (academias, clubes, serviços individualizados) devido às mudanças e atuais exigências do mercado de trabalho, alterações foram sinalizadas no processo de formação e o curso foi dividido em licenciatura (atuação nos espaços escolares) e bacharelado (atuação profissional fora da escola), para de fato atender àss demandas específicas da formação humana curricular na escola e às demandas que extrapolam os limites dessa instituição. Mas entremeio à discussão acerca do projeto de formação, o fato é que ainda hoje há uma disputa pelas Diretrizes Curriculares Nacionais (DCN's) do campo acadêmico da EF (CASTELLANI FILHO, 2016; DE SOUZA NETO, 2016). 


\section{ENSINO MERCANTIL ASSOCIADO À IDEOLOGIA DO CAPITAL HUMANO}

Desde a Revolução Industrial no século XVIII, a educação está relacionada às demandas do mercado e do lucro. A gênese da escola também acontece ao longo desse século junto com a ascensão da burguesia como classe social hegemônica. No plano discursivo ideológico, a burguesia representa a escola como uma instituição pública, gratuita, universal e laica. Mas ao mesmo tempo seu papel esteve articulado à integração das novas gerações na sociedade moderna, socialização de forma sistemática do conhecimento científico, contraposição ao pensamento dominante da sociedade feudal, dominado pela igreja (por isso a defesa pela laicidade), e acima de tudo, reprodução dos conhecimentos, valores, e atitudes necessárias à construção do sistema capitalista (FRIGOTTO, 2011).

Com o término da II Guerra Mundial em 1945, uma das estratégias para evitar a penetração do ideário socialista, bem como o risco de sua expansão, foi pela via da teoria sustentada por Schultz (1973), de que o investimento dos países, famílias e indivíduos na educação seria a única via para a diminuição da desigualdade social.

Theodoro Schultz desenvolveu a Teoria do Capital Humano (TCH) nos Estados Unidos ao longo da década de 1950 para demonstrar o valor econômico da educação. Com essa teoria, a educação passou a ser entendida como algo não meramente ornamental, de fruição, mero bem de consumo, mas algo decisivo do ponto de vista do desenvolvimento econômico, um bem de produção. Partindo da premissa de que o homem educado produz mais, à educação coube o papel de formar recursos humanos para atender às demandas econômicas do país, através da intervenção do estado (SCHULZ, 1973). Educar significa,

\section{[...] revelar ou extrair de uma pessoa algo potencial e latente; significa aperfeiçoar uma pessoa, moral e mentalmente, de maneira a torná-la suscetível de escolhas individuais e sociais, e capaz de agir em consonância; significa prepará-la para uma profissão, por meio de instrução sistemática (SCHULTZ, 1973, p. 18).}

O investimento em educação significava um retorno igual ou maior que outros investimentos produtivos. Ela passou então a ser vista como uma forma de apropriação de capital, e o homem como força de trabalho necessária para os diferentes níveis de qualificação técnica. Era uma tábua de salvação para os países subdesenvolvidos e para mobilidade social das populações pobres (SCHULZ, 1973). Sob a égide da TCH, são traçadas políticas educacionais pautadas na afirmativa de que a ascensão e mobilidade social têm um caminho garantido via escolaridade. Mas segundo Frigotto (2011),

\footnotetext{
A noção de capital humano orienta processos educativos antagônicos à visão da educação básica unitária pelo fato da mesma se orientar por uma concepção de sociedade na qual ignora as relações desiguais de poder, uma concepção de ser humano reduzida ao indivíduo racional que só depende dele as escolhas que faz independente da classe ou grupo social a que pertence e, uma redução da concepção de educação e conhecimento pelo fato dos mesmos não estarem referidos ao desenvolvimento de todas as dimensões da vida humana e vinculados às necessidades humanas, mas à esfera unidimensional das necessidades do mercado e do lucro (p. 23).
}

(C) ETD- Educação Temática Digital

Campinas, SP v.23

n.1

p. 82-97

jan./mar. 2021 
Ademais, para a manutenção de uma aparência de racionalidade em um sistema capitalista cada vez mais irracional, os Estados nacionais têm transferido o governo para os grandes grupos econômicos e para os OI, que dão as diretrizes das políticas educacionais de modo a garantir o lucro, em especial do capital financeiro, no intuito de educar intelectuais para serem âncoras e ideólogos do neoliberalismo educacional nos países em desenvolvimento. As consequências recaem para os trabalhadores que estão no chão da escola e para os estudantes que recebem uma formação alienada, fragilizada e colonizadora. E essa mudança é realizada com o consentimento da população que é "convencida" pelos intelectuais orgânicos do sistema capitalista de que esse é o único sistema possível. Neste contexto de uma educação para o capital (MESZÁROS, 2008), temos as políticas educacionais e a implementação da EAD submetidas às suas exigências ideológicas e econômicas.

\section{METODOLOGIA}

Esta é uma pesquisa qualitativa, do tipo descritivo-exploratório, construída a partir de sucessivas aproximações com os elementos categoriais constitutivos do materialismo histórico-dialético, salvo os limites desta pesquisa. As categorias que utilizamos na investigação percorrida neste artigo foram: totalidade, historicidade, trabalho e contradição (PAULO NETTO, 2011).

$\mathrm{Na}$ perspectiva epistemológica do materialismo histórico-dialético, o pesquisador precisa ir além da aparência fenomênica, imediata e empírica (por onde habitualmente se inicia o conhecimento) para apreender a essência (ou seja, estrutura e dinâmica) do objeto (MARX, 2008; PAULO NETTO, 2011).

A categoria da totalidade nos permite compreender que o objeto de estudo está situado num todo e portanto, a pesquisa precisa estabelecer uma visão interligada que identifique o conjunto de fatores que se relacionam com o objeto, conferindo-lhe historicidade, haja vista estar situado no mundo do trabalho do qual emanam as contradições.

Pela sua amplitude, esta pesquisa optou por realizar um estudo de caso que consistiu em identificar e analisar as tendências ideológicas dos cursos de licenciatura em EF a distância no contexto do âmbito público e privado do Estado de Goiás, excetuando-se o Distrito Federal devido à sua proximidade com os pesquisadores.

O conceito de Ideologia ora adotado também é derivado do materialismo históricodialético a partir dos estudos de Marx (2008), Meszaros (2008) e Chaui (2008), como vimos na introdução. Para Chaui (2000), a ideologia é um corpo de representações (ideias e valores) e de normas e regras (de conduta) que prescrevem aos membros de uma sociedade o que devem pensar, sentir e fazer. Sua função é dar explicações do porquê as diferenças sociais ocorrem omitindo, no entanto, as razões que estão na sua raiz : a esfera econômica. Sua função, portanto, é ocultar a dominação de classe.

Quanto ao recorte empírico, constatou-se que em 2017 existia a oferta de 06 (seis) cursos de licenciatura a distância no Estado de Goiás, sendo eles respectivamente ofertados pelas instituições e iniciados no referente ano: Centro Universitário Claretiano (CEUCLAR) -

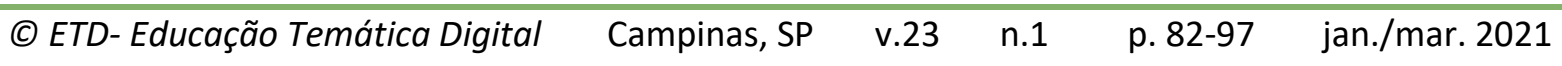


2009/1; Universidade Federal de Goiás (UFG) - 2009/1; Universidade Pitágoras Unopar 2014/1; Universidade Anhanguera (UNIDERP) - 2015/1; Universidade Cruzeiro do Sul (UnicSul) - 2016/1; e Centro Universitário (UniCesumar) - 2016/1.

Todavia, no início desta pesquisa em 2014, existiam apenas três IES que ofertavam licenciatura em EF a distância, sendo uma pública e duas privadas. Em busca de contato com as duas instituições privadas, apenas uma foi receptiva, por isso a pesquisa foi realizada nesta e na única instituição pública.

Para a coleta de dados, foram utilizadas as técnicas da pesquisa documental e de campo. A pesquisa documental foi realizada para coleta e análise do projeto político pedagógico (PPP) ou Guia de Percurso, como é denominado pela Unopar. E a pesquisa de campo (entrevista semiestruturada), não exaustiva, foi realizada com uma pequena amostra dos agentes diretamente responsáveis pelo processo de formação desses estudantes. Nessas entrevistas buscou-se investigar: a rotina dos tutores, os entraves e possibilidades, o rompimento com a lógica esportiva, a influência do mercado fitness, os diferentes tipos de currículo, as referências bibliográficas do curso e o protagonismo dos estudantes quanto aos seus anseios, reflexões críticas, debates e demais questões políticas e pedagógicas. Denominamos a fala dos sujeitos entrevistados como Entr.Publ.1, Entr.Publ.2, Entr.Priv.1 e Entr.Priv.2.

\section{CONSIDERAÇÕES EM TORNO DA LÓGICA DO CAPITAL HUMANO NO PÚBLICO E NO PRIVADO NA FORMAÇÃO DE PROFESSORES DE EF A DISTÂNCIA}

Buscando atender ao objetivo de identificar e analisar as tendências ideológicas dos cursos de licenciatura em EF a distância público e privado, este tópico apresenta a análise e interpretação dos dados coletados na pesquisa documental e de campo.

Nessa análise considerou-se atendimento aos objetivos da pesquisa: análise do PPP's dos cursos, os referenciais teóricos discutidos e a exploração dos instrumentos de linguagem que são utilizados para mascarar o real sentido da educação para o capital. A estrutura dos cursos, o processo formativo e as influências que sofrem os currículos foram estudados por meio de análise descritiva e interpretativa, observadas as aproximações, distanciamentos, contradições e conflitos evidenciados no contexto dos cursos de licenciatura em EF a distância público e privado.

Em relação ao funcionamento de cada curso a partir dos seus objetivos, dinâmica curricular, estruturação docente e atividades avaliativas percebeu-se que o curso da IES privada oferece condições satisfatórias para funcionar, pois não há dificuldades com infraestrutura física e material. Mas, apesar dessa infraestrutura funcionar, os próprios tutores expressaram insatisfação em relação à insuficiência e aprofundamento da formação. Está tudo pronto do mesmo jeito para todos os alunos, o pacote do curso já está pronto. Os tutores presenciais alertam que eles não têm qualquer autonomia na construção do material, mas ainda assim assumem o protagonismo do professor por ser a pessoa que está mais perto e acessível ao estudante. Contudo, exterioriza que sua rotina de trabalho é simples e

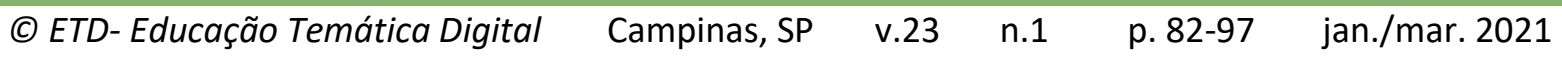


tranquila. Não há relatos de comunicação entre os docentes (tutores e professor especialista). Cada um realiza sua atividade individualmente no decorrer do curso.

Na IES pública, por vezes há dificuldade com a infraestrutura física e material. Os polos se localizam no interior e em alguns casos o sinal da internet é ruim, além do que a adequação do espaço (responsabilidade do município) não é o solicitado pela universidade. No entanto, ao contrário da IES privada, nessa instituição os orientadores demonstram satisfação com a proposta do curso, mesmo com algumas dificuldades e desconfortos provocados pela própria política da Universidade Aberta do Brasil (UAB) ${ }^{3}$. Relatam que apesar do material de aula ser elaborado pelo professor supervisor, o orientador acadêmico tem autonomia e protagonismo na atuação docente. Há comunicação entre tutores e professor especialista. Mas os entrevistados alertam que também acontece de os estudantes direcionarem perguntas para os tutores presenciais, que dificilmente conseguem se apropriar de forma aprofundada do conteúdo de todas as disciplinas, até porque não é esse seu papel na estruturação docente da EAD. Em que pese terem mais autonomia, reclamam do não reconhecimento acadêmico, financeiro e social da sua função, fazendo com que a EAD seja um trabalho extra para muitos tutores, orientadores e professores.

Sobre o processo formativo e as influências que sofrem os currículos, no aspecto do rompimento com a lógica esportiva no currículo, percebe-se que há equivalência no discurso de ambos os cursos sendo contrários à ideia do esportivismo nas aulas de EF. Na UFG, o objetivo estaria no âmbito de,

(...) formar professores com capacidade para atuar e refletir criticamente acerca de sua função formadora, pedagógica, científica, política e social; atuar nos diferentes espaços e dimensões da Educação Básica, dentro da perspectiva da práxis pedagógica e social (...) (MEC, 2011, p.4-5)

E na Unopar, o objetivo do curso também se apresenta numa perspectiva de formação ampliada, propondo,

(...) formar profissionais que possam atuar nos diferentes níveis e modalidade de ensino, em instituições educacionais públicas e privadas, sintonizadas com as novas abordagens e tendências metodológicas de modo a promover o desenvolvimento humano nas dimensões biológicas, sociais, culturais, didático-pedagógicas, técnicoinstrumentais do movimento humano (...) criar perspectivas de uma visão ampla do contexto sócio-político-educacional; atender as atividades escolares em forma de exercícios ginásticos, jogos, esportes, danças, lutas e atividades lúdicas (...) (GUIA DE PERCURSO, 2007, P.6-7)

\footnotetext{
${ }^{3}$ A UAB é um projeto criado em 2005, oficializado em 2006, pelo Ministério da Educação com o objetivo de ampliar o acesso ao ensino superior, oferecendo cursos e programas de educação a distância em parceria com as universidades públicas, municípios e estados da Federação (BRASIL,2006). A infraestrutura física e material os polos, e a precariedade do trabalho docente a partir do papel da tutoria, estão relacionadas dentre as dificuldades e os desconfortos provocados pela política (BRITO, 2011; PIMENTEL, 2013).
} 
Porém, pela análise discursiva dos entrevistados da IES privada, entendemos que estes não sabem ao certo qual a leitura que os alunos fazem dessa intencionalidade, já que muitos têm um objetivo e um foco profissional pré-definido, e que de fato o que vai determinar a abordagem que o professor vai trabalhar é o mercado de trabalho.

(...) meus alunos vêm de uma militância no esporte muito forte, então o cara do futebol consegue dar uma aula de futebol (...) aqui o nicho de mercado é para ex atleta, ex jogador de futebol, vôlei, jogou fora do brasil (...)70\% vem de militância em alguma modalidade esportiva e os demais já conhecem e gostam de fazer aula esportiva. Para a faculdade eu acho pouco, mas é o que eu coloco para os meus alunos, você quer se especializar em algum esporte, vá procurar o curso específico daquele esporte, você quer aprender vôlei, procure a federação, se aprofunde em regras e arbitragem (Entr.Priv.2).

O fato do mercado de trabalho, no caso a escola, ainda guardar forte relação com o ensino do esporte, pode ter refletido na análise dos tutores da IES privada acerca dos encontros presenciais. Seus discursos apontam que esses encontros são suficientes pelo fato dos estudantes serem ex-atletas ou já terem vivência prévia com as práticas corporais. Mas se EF não é só esporte, aparece aí uma contradição no que tange ao entendimento do que seria o papel da EF na escola.

(...) para eles que não vão trabalhar o conteúdo de alto rendimento na escola é suficiente, porque na escola te dão essa abertura, eu não tenho que trabalhar aprofundamento com um grupo escolar onde nem todos os alunos se atraem (...) Então eu vejo que dentro do contexto prático é pouca coisa é, eles vem com muita coisa de fora, não bagagem científica, uma bagagem prática, de saber como que joga" (Entr.Priv.2).

Por outro lado, enquanto na IES privada os encontros presenciais parecem ser meramente funcionais à determinada prática corporal, na IES pública há uma compreensão mais ampla, pois são tidos enquanto um espaço que os estudantes manifestam suas dúvidas, e aprofundam as relações interpessoais e debates acadêmicos. Por isso, apontam os orientadores acadêmicos que estes encontros ainda são insuficientes, em quantidade e produtividade. $O$ discurso da prática profissional embasada no saber-fazer, aliado do discurso da pós-modernidade, não se evidencia na IES pública.

(...) é preciso ficar claro para o aluno que os saberes e experiências não são suficientes para que um professor atue em uma escola ou em uma academia de ginástica. O professor que não dialoga com o conhecimento produzido pelo campo científico está equivocado (...) a atuação profissional não se faz apenas a partir da sua experiência, a docência tem uma natureza específica e complexa (Entr.Publ.2).

(...) deveria ter mais encontros presenciais, mais aulas práticas, e mais produtivos, não só da parte dos professores e tutores a distância e presenciais, mas também dos alunos, porque muitas vezes o encontro presencial se perde, embora você tem uma proposta para encontros de quatro, cinco horas você vê que tem aluno que tem muito mais comprometimento que os alunos do presencial mas também tem muito aluno que não (Entr.Publ.1). 
Talvez uma melhor forma de começar seria com cursos semipresenciais, que tivesse mais encontros presenciais e alguns a distância, talvez isso fosse mais produtivo em um contexto que nós também estamos aprendendo a trabalhar com a EAD. Nós fizemos o inverso, colocamos a maior parte da carga horária a distância e uma menor carga presencial, então acho que isso impacta diretamente na formação dos estudantes (Entr.Publ.2).

Sob a influência do mercado fitness neste contexto de formação, ambos os cursos afirmam ser este um curso voltado para a escola, portanto, de licenciatura, como propõe o PPP. A IES pública relata que a discussão sobre as práticas corporais do mundo e o discurso da área da saúde acabam sendo abordadas porque não é interessante ficar alheio a estas questões, mas garantem não influenciar na grade curricular.

Tem a disciplina de anatomia, fisiologia, biomecânica, EF e saúde, mas tudo voltado para o contexto escolar (...) e essas disciplinas já tinham no currículo, então não pode dizer que foram criadas só para atender essa demanda (Entr.Publ.1).

(...) esses assuntos estão presentes no currículo, mas não como campo de reserva profissional (...), mas porque esses assuntos são pertinentes e precisam estar presentes e ser abordados no currículo (Entr.Publ.2).

Já na IES privada, a preocupação parece não se articular com a discussão política e sim com a reserva de mercado. E neste caso, para evitar que os alunos (que já tinham planejado atuar fora da escola) desistam do curso, utilizam o discurso da empregabilidade, no qual o indivíduo precisa somar atributos para sua permanência no mercado de trabalho. Portanto, de acordo com o discurso da IES privada, o ideal é o estudante cursar licenciatura e posteriormente fazer a complementação do bacharelado.

(...) porque, por exemplo, você faz licenciatura e aparece uma oportunidade excelente para você no bacharelado para ganhar bem (Entr.Priv.1)

Eu digo olha, professor de academia tem data de validade, você precisa criar um nicho de mercado, possibilidade de ir para a escola (...) porque academia é bom quando você está fortinho, arrumadinho, aparência física, o aluno de academia quer ver seu corpo no outro e aí imagina que um professor gordinho não faz carreira (Entr.Priv.2).

Em relação aos tipos de currículo, os entrevistados da IES privada compreendem que a formação para a emancipação crítica do sujeito depende relativamente do próprio sujeito. Segundo eles, os estudantes já vêm com uma concepção fechada e formada de cultura, família e trabalho, sendo difícil competir com os meios de comunicação, além do fato da instituição não ter tempo suficiente para isso. Desta maneira, o curso oferece apenas uma orientação, uma fundamentação básica. A interpretação fica sob responsabilidade do sujeito.

(...) não é fácil o indivíduo hoje ter uma formação crítica e sair de uma situação para se emancipar, ainda mais no ensino superior porque já vem de uma sociedade, de uma cultura, família, que muitas vezes contribuiu para ele ter essa formação (...) ser crítico hoje é difícil demais (...) (Entr.Priv.1).

(...) o curso te dá orientação, fundamentação básica que dá para você ter um entendimento sobre o assunto que está sendo tratado. Cabe ao aluno ter um pouco

(C) ETD- Educação Temática Digital

Campinas, SP v. 23

n.1

p. $82-97$

jan./mar. 2021 
mais um conceito de criticidade, ter uma ideia, buscar algo mais bacana para sua aula (Entr.Priv.2).

Diante destas circunstâncias do curso da IES privada, em cada disciplina existem leituras específicas, sem necessariamente se vincular a uma determinada matriz de conhecimento, e de preferência mais efêmeras, curtas, como artigos, textos, notícias, para não complicar e causar conflitos desnecessários.

(...) a questão de leitura desses alunos, $80 \%$ não lê, muitos nem entraram na biblioteca assim como no presencial também acontece (...) através da escrita dá para ver que a leitura é muito pobre (...)" (Entr.Priv.1)

(...) no cunho científico tem menos leitura que o presencial, e deixa um pouco a desejar (...)" (Entr.Priv.2).

Quando os assuntos são tratados de maneira fragmentada, dificilmente gera debates, que no caso também são inexistentes, acentua o Entr.Priv.2.

Eu acho que os professores de Londrina não geram essa discussão (crítica), primeiro porque vai gerar um conflito, estar provocando, mexendo com uma caixa de marimbondo e essa caixa de marimbondo gera um conflito maior (...) (Entr.Priv.2)

Já na IES pública, salvo os limites da investigação empírica, as leituras estão articuladas na constituição de uma teoria do conhecimento de base epistemológica crítica-dialética, a partir dos mesmos referenciais progressistas do ensino presencial.

(...) o currículo da EAD é um currículo progressista ${ }^{4}$, tem uma visão de homem, sociedade, do que busca na formação, o que espera que se forma dos professores no trabalho com os alunos (...), um ensino de EF muito além do rolar bola, do esporte espetáculo, um movimento crítico mesmo de pensar a realidade, o ser nessa realidade, o de transformar essa realidade para atuar no sentido de criar e formar cidadãos críticos e autônomos (...) (Entr.Publ.1)

O currículo do ensino a distância tem a proposta de formação crítica apesar de alguns problemas operacionais, e às vezes de dificuldade do processo de ensino e aprendizagem, mas propõe essa emancipação crítica principalmente porque leva o aluno a refletir e entender a realidade (...) (Entr.Publ.1)

Os referenciais que embasam o curso de licenciatura em EF a distância são os clássicos da década de 80 , início da década de 90, nesse processo de redemocratização da sociedade brasileira que de certa forma influenciou significativamente a formação no campo da EF (Entr.Publ.2)

(...) então o curso por mais que ele tenha certa característica epistemológica ele ainda vai dialogar com os clássicos da área que são divergentes (...) quando você trabalha com autores de diferentes áreas você dá possibilidade de compreender diferentes formas de leitura sobre o campo de conhecimento (Entr.Publ.2)

\footnotetext{
4 Em consonância com o PPP da UFG, que relaciona ter como finalidade: "implementar uma proposta progressista na formação de professores, com inserção qualitativa na escola e nas demais práticas educativas, pedagógicas e sociais que envolvem as práticas corporais na sociedade" (MEC, 2011, p.1).
}

(C) ETD- Educação Temática Digital Campinas, SP $\quad$ v.23 $\quad$ n.1 $\quad$ p. 82-97 jan./mar. 2021


Os orientadores relatam que apesar dos conflitos, dificuldades, desconfortos e resistências, a IES pública tem um projeto formativo para a emancipação crítica do sujeito e aponta terem tido já experiências exitosas com a formação.

\section{CONSIDERAÇÕES FINAIS}

Ainda que não seja um estudo didático-pedagógico, há indicativos de que a IES privada apresenta certa superficialidade teórica dos conteúdos, ocultamento de que as concepções educacionais, os métodos pedagógicos e a organização curricular de um curso influenciam diretamente no tipo de formação humana, o que foge, nesse caso, da responsabilidade do sujeito.

Segundo Chaui (2008), um dos aspectos que torna a ideologia uma força difícil de remover é a separação entre trabalho material e trabalho intelectual. "Enquanto o trabalhador for aquele que "não pensa" ou que "não sabe pensar" e o pensador for aquele que não trabalha, a ideologia não perderá sua existência e nem sua função (p. 82)".

A apreciação pelas práticas nas disciplinas curriculares em detrimento do conhecimento teórico/reflexivo busca associar a figura do professor a um profissional da prática, desintectualizando sua função que é muito mais complexa do que está colocado. Esses entendimentos legitimam o discurso ideológico da pós-modernidade de ajustamento do conhecimento à relação mercadológica.

As organizações e instituições, ao conceberem a educação como um negócio lucrativo, passaram a investir cada vez mais no mercado educacional, fato evidenciado pela expansão da oferta de cursos pelas IES privadas e pelo faturamento de grupos econômicos.

Esse diagnóstico é desastroso, pois reflete a adoção de critérios mercantis na gestão, na escolha das disciplinas que compõem o currículo, na definição dos conteúdos, nos métodos de ensinar e avaliar; situações que implicam em consequências observadas nesta pesquisa, de um curso na IES privada em questão, totalmente voltado para atender ao mercado de trabalho para o qual não há direitos, mas competição e a lei do mais forte. A formação para a crítica e emancipação do sujeito parece não ser um objetivo presente e atrativo nesse contexto.

O cenário da educação se desenvolvendo a partir dos parâmetros do capital é característico tanto da educação privada quanto da pública, e se expande invadindo territórios e mentes, adaptado às transformações da sociedade capitalista, fundada no pragmatismo e na razão instrumental.

Como já ressaltado anteriormente, apesar deste não ser um estudo didáticopedagógico, na IES pública são perceptíveis indícios de uma preocupação com os princípios políticos, éticos e pedagógicos pertinentes a uma formação crítica e emancipadora para a formação do sujeito; de uma EF voltada para atuação em ambientes escolares, com uma proposta focada na importância do saber sobre o saber-fazer e sua contextualização pedagógica. 
O problema que se instala é que a atual política educacional brasileira não oferece as condições ideais para a condução do curso (qualificação da função do professor, estrutura dos polos, quali/quantidade de encontros presenciais). O contexto e a justificativa de criação da política da UAB correlacionam-se mais aos interesses do mercado do que necessariamente em ampliar o acesso à universidade e ao conhecimento elaborado.

Enquanto o curso público tem um preordenamento para que o aluno possa produzir conhecimento e não somente reproduzir a informação, a logística da política da UAB é prédeterminada para estabelecer obstáculos para uma proposta de formação com qualidade. Segundo lanni (2004),

Tudo que diz respeito à educação passa a ser considerado como uma esfera altamente lucrativa de aplicação do capital, o que passa a influenciar decisivamente os bens e os meios envolvidos; de tal modo que a instituição de ensino, não só a privada como também a pública, passa a ser organizada e administrada segunda a lógica da empresa, corporação ou conglomerado (p.112).

Logo, é possível aduzir nos limites desta pesquisa que o problema não é a especificidade da formação de professores de EF a distância, mas a forma como foi constituída a política, a qual está intrinsecamente relacionada à ideologia do capital humano e dos $\mathrm{OI}$. $\mathrm{E}$ esses organismos, ofertando um discurso ideológico neoliberal, atendem aos interesses da classe dominante, sob os princípios da racionalidade, eficiência, eficácia, flexibilidade e produtividade.

Diante dessas questões, espera-se que esta pesquisa possa fomentar novos estudos no campo de formação de professores de EF a distância, atendo-se às mudanças que vêm ocorrendo no processo produtivo, aos efeitos da política neoliberal que colocam o mercado como o centro do universo e à própria universidade, que tem cedido espaço para uma educação empresarial subsidiada por interesses do capital internacional.

Ao se pensar num projeto de formação, é clarividente que os currículos ou projetos pedagógicos devem se pautar na reflexão crítica, no combate à ideologia do consumo, descartável e de fruição rápida, e na ideia da cultura hegemônica burguesa como expressão universal. A reflexão crítica precisa se fundamentar na perspectiva da socialização da cultura elaborada, numa formação que desenvolva todos os campos do conhecimento, autonomia e capacidade de análise da sociedade em que se vive.

Essa concepção de educação é antagônica à concepção mercantil, fragmentária e pragmática da qualidade total, empregabilidade, da pedagogia das práticas (BM), que tem se efetivado enquanto política educacional do país, e que demarca a formação de professores de EF a distância.

Mas esta luta implica na organização da classe trabalhadora; implica no aprofundamento da formação teórica numa perspectiva histórica (dialética) e na solidificação das organizações sociais e políticas; implica numa luta contra hegemônica; implica numa luta, sobretudo, de caráter ético-político. 
Chaui (2008) assinala que um aspecto da existência histórica dos homens é a ação de reproduzir ou transformar as relações sociais existentes. A história depende do modo como os homens "determinados em condições determinadas criam os meios e as formas de sua existência social, reproduzem ou transformam essa existência social que é econômica, política e cultural (p.23)".

Em outras palavras, uma ideologia não possui um poder absoluto que não possa ser quebrado e destruído. Quando uma classe social compreende sua própria realidade, pode organizar-se para quebrar uma ideologia e transformar a sociedade. Os burgueses destruíram a ideologia aristocrática (nos séculos XVI, XVII e XVIII), e os trabalhadores podem destruir a ideologia burguesa (como propôs Marx) (CHAUI, 2008, p.24-25).

É preciso buscar processos educativos cujo horizonte, como aponta Meszáros (2008), seja capaz de ir além das relações sociais capitalistas, capaz de dignificar a profissão docente e garantir o direito a educação.

Por fim, com essa pesquisa conseguimos apontar e desvelar que as tendências ideológicas da formação de professores de EF estão sinalizadas para o mercado de trabalho: líquido, flexível, onde se ampliam as práticas fitness ou esportivas efêmeras para a busca da beleza, juventude e qualidade de vida, relegando à escola o mínimo de preocupação com a formação humana para a emancipação. Essa razão instrumental evidencia-se de forma bastante acentuada na IES privada e menos proeminente na IES pública. Nesta última, devese ao enfrentamento dos fatores internos em relação às questões pedagógicas, mas a incapacidade de atuar na constituição da política da UAB impede uma ação formativa mais comprometida com o PPP. Com isso, temos que o problema não é a modalidade a distância em si, mas a concepção de que sob o domínio do capital, a EAD se torna um negócio muito lucrativo, e por conseguinte compromete a qualidade da educação.

\section{REFERÊNCIAS}

AMARAL, Gislene Alves do. et.al. Formação profissional e diretrizes curriculares da educação física. Revista Especial dee Educação Física. Edição Digital, v.3, n.1, nov., 2006.

BRACHT, Valter. Esporte na escola e esporte de rendimento. Revista Movimento, Porto Alegre, v. 0, n. 12, p. xiv-xxiv, 2000.

AZEVEDO, Renato Ribeiro; BERGMANN, Gabriel Gustavo. O esporte e o seu protagonismo na educação física escolar: experiência e reflexões do Programa Institucional de Bolsas de Iniciação à Docência. DO CORPO: Ciências e Artes, Caxias do Sul, v. 1, n. 3, 2013.

BANCO MUNDIAL. Pryoridades y strategias para la educacion. Washington, D. C.: Examendel Banco Mundial, 1996.

BRACHT, Valter. A constituição das teorias pedagógicas da educação física. Cadernos CEDES, Campinas, v. XIX, n. 48, p. 69-88, 1999. 
BRITO, Eliana Póvoas Pereira Estrela. O sistema universidade aberta do Brasil e as políticas de formação de professores. Cadernos de Pesquisa, v.6, n.13, maio-jul. 2011.

CAPARROZ, Francisco Eduardo. Entre a educação física na escola e a educação física da escola. 3.ed. Campinas, SP: Autores Associados, 2007.

CASTELLANI FILHO, Lino. A formação sitiada. Diretrizes curriculares de EF em disputa: Jogo jogado? Pensar a Prática, Goiânia, v. 19, n. 4, out./dez. 2016.

CHAUI, Marilena. O que é ideologia? 2.ed. São Paulo: Brasiliense, 2008. (Coleção primeiros passos).

COLETIVO DE AUTORES. Metodologia do ensino da educação física. São Paulo: Cortez, 1992. (Coleção Magistério $2^{\circ}$ grau - série formação do professor)

DOURADO, Luis Fernandes. Políticas e gestão da educação superior a distância: novos marcos regulatórios? Educação e Sociedade, v. 29, n. 104, p. 891-917, especial, Campinas, out. 2008.

FRIGOTTO, Gaudêncio. Novos fetiches mercantis da pseudoteoria do capital humano no contexto do capitalismo tardio. In.: ANDRADE, J. de (Org.); PAIVA, L. G. de (Org.). As políticas para educação no Brasil contemporâneo: limites e contradições. Juiz de Fora, Ed: UFJF, 2011.

GUIA DE PERCURSO UNOPAR. Curso de EF Licenciatura em EF. Ingressantes a partir de 2014/1. 2017. Disponível em: https://docplayer.com.br/7759834-Curso-de-educacao-fisicalicenciatura-em-educacao-fisica-ingressantes-a-partir-de-2014-1.html. Acesso em: 19/03/2020.

IANNI, Octavio. Capitalismo - violência e terrorismo. Rio de Janeiro: Civilização Brasileira, 2004.

MALANCHEN, Julia. UNESCO: Políticas e estratégias para formação docente a distância no Brasil. Revista HISTEDBR On-line, Campinas, n.32, dez. 2008. p.179-199.

MARX, Karl. Contribuição à crítica da economia política. Tradução e introdução de Florestan Fernandes. 2.ed. São Paulo: Expressão popular, 2008.

MESZÁROS, István. Educação para além do capital. 2 ed. São Paulo: Boitempo, 2008. MINISTÉRIO DA EDUCAÇÃO. Projeto político-pedagógico do curso de licenciatura em Educação Física na modalidade de ensino à distância. Universidade Federal de Goiás. Faculdade de Educação Física. 2011. Disponível em: https://www.fefd.ufg.br/n/7994projeto-politico-pedagogico-ead-em-educacao-fisica?locale=es. Acesso em: 19/03/2020.

PAULO NETTO, José. Introdução ao estudo do método de Marx. São Paulo: Expressão popular, 2011. 
PALAFON, Gabriel Humberto Nuñoz. As tendências pedagógicas em EF e sua relação com as categorias idealistas e materialistas da história. Revista Motrivivência, UFSC, Florianópolis, SC, Ano VI, v.4, jun/1993.

PIMENTEL, Fernanda Cruvinel. A experiência da Universidade de Brasília no contexto de expansão da licenciatura em Educação Física por meio do Sistema Universidade Federal de Goiás. 2013. Dissertação (Mestrado em Educação Física) - Faculdade de Educação Física, Universidade de Brasília, Brasília, DF, 2013.

SCHULTZ, Theodore. 0 capital humano: investimentos em educação e pesquisa. Tradução de Marco Aurélio de Moura Matos. Zahar, Rio de Janeiro, 1973.

SOARES, Carmem Lucia. Educação física: raízes europeias e Brasil. 3. ed. Campinas, SP: Autores Associados, 2004 (Coleção educação contemporânea).

SOUZA NETO, Samuel et al. A formação do profissional de Educação Física no Brasil: uma história sob a perspectiva da legislação federal no século XX. Revista Brasileira de Ciências do Esporte. Campinas, v. 25, n. 2, p. 113-128, jan. 2004.

Conflitos e tensões nas diretrizes curriculares de Educação Física: o campo profissional como um espaço de lutas e disputas. Pensar a Prática, v.19, n.4, 2016. https://doi.org/10.5216/rpp.v19i4.42263

VAGO, Tarcísio Mauro. Esporte da escola, esporte na escola: da negação radical à tensão permanente - um diálogo com Valter Bracht. Revista Movimento, Porto Alegre, n. 5, p. 4-17, 1996.

Revisão gramatical realizada por:

Danillo Cruvinel Pimentel.

E-mail: danvila25@gmail.com 